\title{
Post-transplantation primary central nervous system lymphoma in a patient with systemic lupus erythematosus and prolonged use of immunosuppressant
}

\author{
Teresa PK Tse *, Allan NL Chan, Tony KT Chan, YC Po
}

\begin{abstract}
A B S T R A C T
Post-transplantation primary central nervous system lymphoma is an uncommon and fatal post-transplant lymphoproliferative disorder. Such lymphomas have been described in only a few case series in the literature. The incidence of this condition is rising with improved survival after organ transplantation. A case of post-transplantation primary central nervous system lymphoma in a young Chinese woman with systemic lupus erythematosus is described here. She presented with right-sided weakness and memory loss after tooth extraction 2 weeks before admission. Contrast computed tomography of the brain demonstrated a contrast rim-enhancing lesion over the left frontal lobe. With a history of recent dental procedure, long-term immunosuppressive therapy and computed tomography findings, cerebral abscess was highly suspected. Emergency operation was performed. Histopathology showed post-transplantation primary central nervous system lymphoma, with cells positive for B-cell marker
\end{abstract}

CD20. Immunosuppressant was stopped and she was treated with radiotherapy and rituximab (antiCD20 monoclonal antibody). She remained diseasefree at 16 months. Post-transplantation primary central nervous system lymphoma is rare with variable presentation and radiological features. We believe rituximab may have a role in the treatment of such lymphomas.

\section{Hong Kong Med J 2014;20:541-4}

DOI: $10.12809 / \mathrm{hkmj} 134095$

TPK Tse *, MB, ChB

ANL Chan, FHKCEM, FHKAM (Emergency Medicine)

TKT Chan, FCSHK, FHKAM (Surgery)

YC Po, FCSHK, FHKAM (Surgery)

Department of Neurosurgery, Princess Margaret Hospital, Lai Chi Kok, Hong Kong

*Corresponding author: teresapoki@hotmail.com, tpk730@ha.org.hk

\section{Introduction}

Post-transplant lymphoproliferative disorder (PTLD) is a rare neoplastic complication of solid organ transplantation, affecting less than $2 \%$ of post-transplant patients. It includes a spectrum of diseases ranging from Epstein-Barr virus (EBV)driven polyclonal lymphoid proliferation to EBVpositive or -negative malignant lymphoma. Posttransplantation primary central nervous system lymphoma (PT-PCNSL) is an uncommon and potentially fatal PTLD that develops in posttransplantation patients with the tumours confined to the brain and spinal cord, affecting $10 \%$ of patients with PTLD, which in turn affects only $1 \%$ of patients with kidney transplantation. The most common form of PCNSL is diffuse large B-cell lymphoma. ${ }^{1,2}$ To date, PT-PCNSL has been described in only case reports and a few case series in the literature. ${ }^{3,4}$ The exact incidence of PT-PCNSL is unknown, but it is expected to be rising in the future with improving survival for patients with organ transplant. ${ }^{5}$ Clinical presentation and radiological features of PT-PCNSL can vary. Here we describe a case of PT-PCNSL in a
Chinese woman with systemic lupus erythematosus (SLE) and prolonged use of immunosuppressant.

\section{Case report}

A young woman with a known history of SLE underwent cadaveric renal transplantation for endstage renal failure at the age of 28 years. She developed a complication of moderate cellular rejection postoperatively and was placed on mycophenolate mofetil (MMF) $750 \mathrm{mg}$ every morning and $500 \mathrm{mg}$ in the afternoon, and prednisolone $5 \mathrm{mg}$ daily since 2000. Her renal function worsened after an episode of acute pyelonephritis in 2010 with creatinine level rising to $210 \mathrm{mg} / \mathrm{dL}$ from $150 \mathrm{mg} / \mathrm{dL}$. She remained well afterwards until December 2011 when she was admitted to our hospital for progressive right-sided weakness and memory loss after tooth extraction 2 weeks before admission. On physical examination, she was found to have expressive dysphasia and right-sided weakness. Urgent contrast computed tomography (CT) of the brain demonstrated a 3.9 $\mathrm{cm} \times 6.4 \mathrm{~cm} \times 4.7 \mathrm{~cm}$ multilobulated contrast rimenhancing lesion in the left frontal region with 


\section{系統性紅斑狼瘡症患者因長期使用免疫抑製劑而 引發的移植後原發性中樞神經系統淋巴瘤 謝寶琪、陳傲麟、陳甘棠、保延聰 \\ 移植後原發性中樞神經系統淋巴瘤（PT-PCNSL）很罕見, 它是一種 可致命的移植後淋巴增殖性疾病。文獻中僅有少數這種淋巴瘤的病 例報導。隨着器官移植後的存活率有所提高, PT-PCNSL的發病率也 有上升的趨勢。本文報告一名系統性紅斑狼瘡症年輕女患者患有PT- PCNSL。她入院前兩星期曾拔牙, 病發時身體右側無力和記憶力減 退。顯影電腦斷層掃描顯示病人左額葉呈邊緣增強病變。由於病人近 期曾接受牙科治療, 加上長期服用免疫抑制治療的病史和電腦斷層掃 描結果, 臨床診斷為腦膿腫, 遂進行緊急手術。組織病理學結果顯示 病人有PT-PCNSL, 其B細胞標誌物CD20呈陽性。病人停止服用免疫 抑製劑, 並接受放療和利妥昔單抗 (抗-CD20單克隆抗體) 治療。病 人於術後 16 個月未有復發跡象。PT-PCNSL很罕見, 其症狀和影像學 特徵也有很大差異。我們相信利妥昔單抗可醫治這種淋巴瘤。}

perifocal oedema and midline shift (Fig 1). With a history of recent dental procedure, long-term immunosuppressive therapy, and CT findings, cerebral abscess was highly suspected. Emergency operation was arranged and intravenous antibiotics were started immediately.

\section{Operation}

Burr hole for tapping of abscess was planned initially. Intra-operative ultrasound revealed an isodense lesion underneath the dura. Tapping was performed thrice but no fluid was aspirated. As frozen section

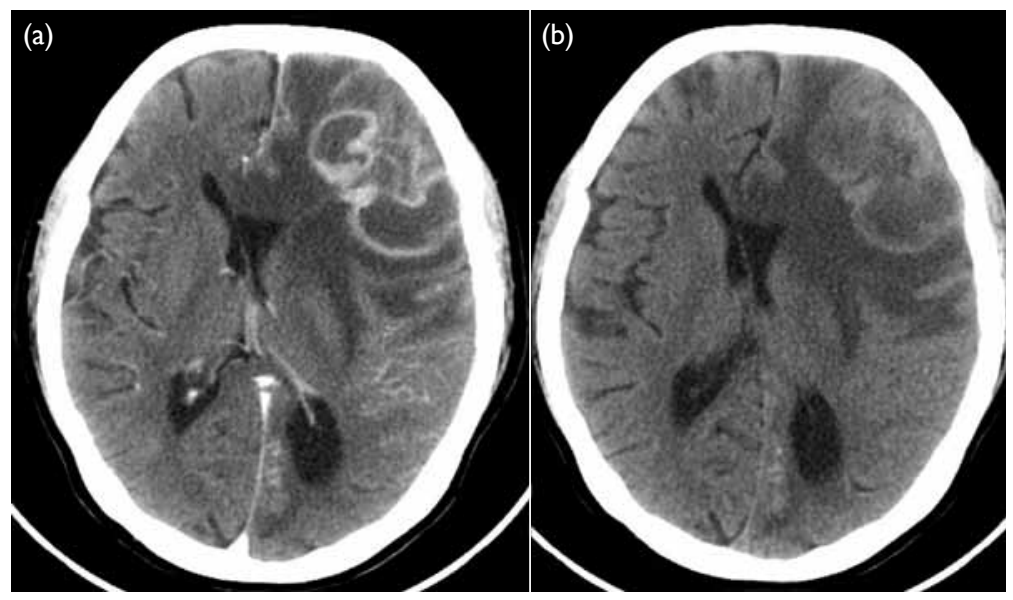

FIG I. (a) Contrast and (b) plain computed tomography of the brain showing a multilobulated lesion in the left frontal region, measuring $3.9 \mathrm{~cm} \times 6.4 \mathrm{~cm} \times 4.7 \mathrm{~cm}$, causing significant mass effect with perifocal oedema, effacement of adjacent sulcal spaces, and resultant right-sided midline shift. It has thin contrast-enhancing rims and non-enhancing central areas. No significant enhancing soft tissue component was associated was unavailable during non-office hours, we decided to perform left frontal craniotomy. Frontal lobectomy with partial excision of lesion was done. The lesion was found to be rubbery, lobulated, and non-vascular.

\section{Pathological findings}

Pathological examination revealed a lymphoproliferative lesion characterised by extensive infiltration by abnormal medium-to-large-sized lymphoid cells with large areas of necrosis. The abnormal lymphoid cells were monomorphic with vesicular nuclei and small nucleoli. The neoplastic cells were strongly positive for B-cell marker CD20. They were also positive for BCL2 and CD30, but negative for CD10 and T-cell marker CD3. In addition, the tumour cells were positive for EBVencoded early RNAs (EBER) and EBV LMP-1. The Ki-67 proliferation index was estimated at $40 \%$ to $50 \%$. The morphological findings, supported by immunohistochemical studies, were consistent with monomorphic PTLD, primary diffuse large B-cell lymphoma of the central nervous system (CNS) [Fig 2].

\section{Postoperative course}

Further workup showed that the patient had isolated CNS lymphoma. Bilateral bone marrow biopsies were done which showed no evidence of lymphoproliferative disease. Postoperative positron emission tomography-computed tomography (PET-CT) revealed residual hypermetabolic left frontal lymphomatous deposits but there were no hypermetabolic foci in the neck, thorax, abdomen, and pelvis. Serology was negative for EBV all along.

Postoperatively, the patient was continued on prednisolone and her antibiotics were discontinued. Mycophenolate mofetil was stopped and she was started on everolimus $0.25 \mathrm{mg}$ daily. In view of suboptimal Karnofsky Performance Score and deteriorating renal function, she was treated with whole-brain radiotherapy (WBRT) alone (40 Gy/20 fr) followed by rituximab consolidation therapy (500 $\mathrm{mg}$, once every 3 week, for 4 weeks). Five months after surgery, PET-CT showed complete resolution of the left frontal hypermetabolic foci; PET-CT 16 months after surgery showed stable disease. She is currently doing well 30 months after operation.

\section{Discussion}

Post-transplantation PCNSL is a rare neoplasm. Its clinical presentation and radiological features can vary. In a case series that involved 33 patients with PT-PCNSL imaged by contrast magnetic resonance imaging (MRI), 41\% had homogeneously enhanced lesions, while $29 \%$ had ring enhancement and $61 \%$ had multiple lesions. ${ }^{6}$ In a review involving 221 


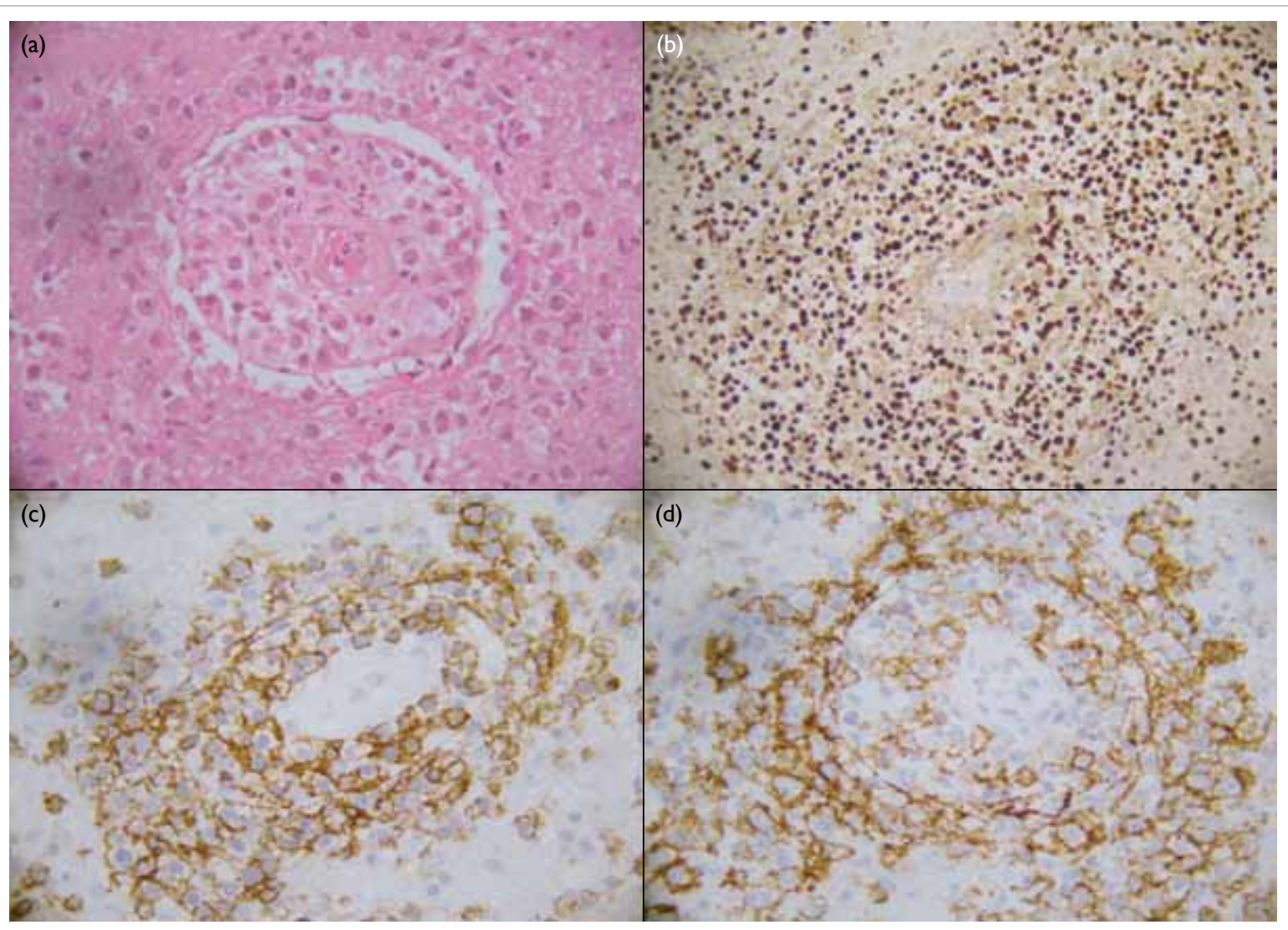

FIG 2. Various findings are shown: (a) tumour cells with prominent perivascular pattern on haematoxylin and eosin staining (x 20), (b) positive results for in-situ hybridisation for Epstein-Barr virus (x 20), and (c) aberrant expression of T-cell marker CD43 (x 20), and (d) positive staining for B-cell marker (x 20)

patients with ring-enhancing lesions on MRI, 40\% were gliomas, $30 \%$ were brain metastases, $12 \%$ were brain abscesses, $6 \%$ were multiple sclerosis plaques, and $2 \%$ were lymphomas. ${ }^{7}$ Imaging modalities such as magnetic resonance spectroscopy (MRS) may aid in differentiating PCNSL from brain abscess. In MRS, PCNSL typically demonstrates a lipid peak with raised choline to $\mathrm{N}$-acetylacetate (NAA) ratio; while abscess typically demonstrates a lactate peak with reduced choline and NAA. Both PCNSL and abscess demonstrate restricted diffusion in diffusionweighted imaging. Nuclear imaging such as PET scan may also help by showing high uptake in PCNSL while the uptake is low in abscess. However, urgent MRI, MRS, and PET scan were not readily available in our centre during non-office hours. In our case, the patient presented with focal neurological deficit with a history of recent dental procedure, use of long-term immunosuppressive therapy, and contrast rim-enhancing lesion on CT. The overall picture was suggestive of cerebral abscess, which warranted urgent surgical drainage.

Systemic lupus erythematosus is associated with an increased risk of haematological cancer, mainly non-Hodgkin's lymphoma, while association with PCNSL is very rare with only few case reports on the condition in the literature. Moreover, most of these cases were associated with serious immunosuppressive therapy. Possible risk factors of PT-PCNSL include high-dose immunosuppressant and negative EBV serologyin the transplant recipient. ${ }^{8}$ Our patient developed PT-PCNSL after kidney transplantation with prolonged use of MMF, and her EBV serology was also negative. It is postulated that EBV seronegativity and immunosuppression may predispose the transplant recipient to a novel EBV infection and, thus, the development of PT-PCNSL. However, the association of PT-PCNSL and SLE remains unclear.

The best treatment of PT-PCNSL has not been established. Reduction of immunosuppressive therapy, WBRT, and chemotherapy with agents like methotrexate and rituximab have been used for treating patients with PT-PCNSL. Wholebrain radiotherapy induced complete response by neuroimaging in $60 \%$ of patients with PCNSL but the median overall survival was only 12 months. ${ }^{9}$ Highdose intravenous methotrexate is now the standard of care for PCNSL with reported overall survival of up to 60 months. ${ }^{10}$ Rituximab, an anti-CD20 
monoclonal antibody, has been used to treat patients with systemic PTLD. As rituximab does not penetrate the blood-brain barrier effectively, its effectiveness in treating PT-PCNSL is doubtful. ${ }^{11}$ Only three studies involving 10 patients with PT-PCNSL treated with intravenous rituximab have been reported with overall survival of at least 20 months. ${ }^{6,12,13}$ Resection of PCNSL has been discouraged as it causes significant neurological deficit without any survival benefit. In our case, after partial resection of tumour, WBRT and rituximab were used to treat PT-PCNSL. The patient remained disease-free at 16 months with MRI showing complete resolution of the lesions; she remains asymptomatic at 30 months after operation. It is believed that rituximab may have a role in the management of patients with PTPCNSL by achieving adequate drug penetration into the brain parenchyma through leaky lymphomatous vasculature. We propose reconsidering the statement that efforts at resection of PCNSL should be discouraged, at least if resection seems safe. Yet, further studies are required to determine the best treatment for PT-PCNSL.

\section{Conclusion}

Post-transplantation PCNSL is a rare neoplasm with variable clinical presentation and radiological features. Possible risk factors include EBV seronegativity and prolonged use of immunosuppressive therapy. We believe rituximab and tumour resection may have a role in the treatment of PT-PCNSL.

\section{Acknowledgement}

We would like to express our special thanks to Dr WL Lam for the pathological examination of the specimen.

\section{Declaration}

No conflicts of interest were declared by authors.

\section{References}

1. Castellano-Sanchez AA, Li S, Qian J, Lagoo A, Weir E, Brat DJ. Primary central nervous system posttransplant lymphoproliferative disorders. Am J Clin Pathol 2004;121:246-53.

2. Vaglio A, Manenti L, Mancini C, et al. EBV-associated leukoencephalopathy with late onset of central nervous system lymphoma in a kidney transplant recipient. Am J Transplant 2010;10:947-51.

3. Phan TG, O’Neill BP, Kurtin PJ. Posttransplant primary CNS lymphoma. Neuro Oncol 2000;2:229-38.

4. Snanoudj R, Durrbach A, Leblond V, et al. Primary brain lymphomas after kidney transplantation: presentation and outcome. Transplantation 2003;76:930-7.

5. Wolfe RA, Roys EC, Merion RM. Trends in organ donation and transplantation in the United States, 1999-2008. Am J Transplant 2010;10:961-72.

6. Cavaliere R, Petroni G, Lopes MB, Schiff D; International Primary Central Nervous System Lymphoma Collaborative Group. Primary central nervous system post-transplantation lymphoproliferative disorder: an International Primary Central Nervous System Lymphoma Collaborative Group Report. Cancer 2010;116:863-70.

7. Schwartz KM, Erickson BJ, Lucchinetti C. Pattern of T2 hypointensity associated with ring-enhancing brain lesions can help to differentiate pathology. Neuroradiology 2006;48:143-9.

8. Caillard S, Dharnidharka V, Agodoa L, Bohen E, Abbott K. Posttransplant lymphoproliferative disorders after renal transplantation in the United States in era of modern immunosuppression . Transplantation 2005;80:1233-43.

9. Nelson DF, Martz KL, Bonner H, et al. Non-Hodgkin's lymphoma of the brain: can high dose, large volume radiation therapy improve survival? Report on a prospective trial by the Radiation Therapy Oncology Group (RTOG): RTOG 8315. Int J Radiat Oncol Biol Phys 1992;23:9-17.

10. Thiel E, Korfel A, Martus P, et al. High-dose methotrexate with or without whole brain radiotherapy for primary CNS lymphoma (G-PCNSL-SG-1): a phase 3, randomised, noninferiority trial. Lancet Oncol 2010;11:1036-47.

11. Ruhstaller TW, Amsler U, Cerny T. Rituximab: active treatment of central nervous system involvement by nonHodgkin's lymphoma? Ann Oncol 2000;11:374-5.

12. Traum AZ, Rodig NM, Pilichowska ME, Somers MJ. Central nervous system lymphoproliferative disorder in pediatric kidney transplant recipients. Pediatr Transplant 2006;10:505-12.

13. Kordelas L, Trenschel R, Koldehoff M, Elmaagacli A, Beelen DW. Successful treatment of EBV PTLD with CNS lymphomas with the monoclonal anti-CD20 antibody rituximab. Onkologie 2008;31:691-3. 